\title{
ACOLHIMENTO À CLIENTELA: ESTUDO EM UNIDADES BÁSICAS DE SAÚDE NO MUNICÍPIO DE RIBEIRÃO PRETO*
}

\author{
Silvia H. Henriques Camelo** \\ Emília Luigia Saporiti Angerami*** \\ Eliete Maria Silva**** \\ Silvana Martins Mishima*****
}

CAMELO, S.H.H.; ANGERAMI, E.L.S.; SILVA, E.M.; MISHIMA, S.M. Acolhimento à clientela: estudo em unidades básicas de saúde no município de Ribeirão Preto. Rev.latino-am.enfermagem, Ribeirão Preto, v. 8, n. 4, p. 3037 , agosto 2000 .

Tendo como referencial teórico o "modelo de ajuda" cujos elementos são: atender, responder, personalizar, orientar, envolver-se, explorar, compreender, agir; realizou-se o estudo analisando o relacionamento que se estabelece entre auxiliar de enfermagem e clientela em duas unidades de saúde enfocando o acolhimento. Quatro casos típicos são apresentados, mostrando que nem sempre as relações são personalizadas, cliente e auxiliar não se envolvem na relação, há maior preocupação com as habilidades técnicas que com acolhimento. Na mesma unidade, há posturas diversas no comunicar-se. O acolhimento ainda deve ser incorporado aos procedimentos das unidades, ao mesmo tempo que deve transcender o caráter rotineiro do cotidiano.

UNITERMOS: enfermagem, processos de enfermagem, relações interpessoais

\section{INTRODUÇÃO}

A partir da Constituição Federal de 1988, na qual foram contempladas as propostas oriundas da $8^{\mathrm{a}}$ Conferência Nacional de Saúde (CNS) - a descentralização da gestão, integralidade das ações, fortalecimento do município, participação da comunidade, regionalização e hierarquização - cada município brasileiro assumiu novas contribuições em relação à saúde.

No final de 1990, a regulamentação do Sistema Único de Saúde (SUS), teve este princípios norteadores: saúde como direito de todos e dever do Estado; universalidade e eqüidade do acesso; superação da dicotomia entre prevenção e cura; integralidade na assistência ao indivíduo; descentralização com gestor único em cada esfera de governo; participação complementar do sistema privado, com preferência para os filantrópicos e os sem fins lucrativos; ênfase nas áreas de saúde do trabalhador, vigilância epidemiológica e sanitária, alimentação e nutrição e portadores de deficiência; participação comunitária efetiva; financiamento tripartite entre União, Estados e Municípios.
O desafio básico para o SUS é atender as necessidades reais da população brasileira. Ele deve buscar equilíbrios dinâmicos entre interesses coletivos e individuais, entre os diferentes atores sociais de um sistema de atenção, entre a eqüidade e a eficiência e entre os controles e liberdades dos profissionais.

Dentro das idéias organizadoras do SUS está a descentralização das ações e decisões sobre a organização e funcionamento, através de sistemas locais de saúde. A descentralização é a forma de levar o processo decisório ao âmbito local, atendendo melhor as necessidades da população, dentro do espaço institucional, tem como dimensão mais marcante o processo de Municipalização. É um processo demorado, já que implica na transformação das estruturas de poder.

A municipalização da Saúde constitui uma alternativa para a mudança organizacional e política do setor público de saúde, na medida em que sua organização permite maior autonomia na gestão dos recursos, principalmente os humanos. Ela oferece melhores condições de controle social, pois o poder local, por estar

\footnotetext{
* Projeto de Pesquisa desenvolvido na Universidade de São Paulo - Escola de Enfermagem de Ribeirão Preto. Subvenciado pelo $\mathrm{CNPq}$

** Bolsista/Aperfeiçoamento - Projeto Integrado CNPq no 52030095

*** Coordenadora do Projeto Integrado de Pesquisa CNPq n 52030095

**** Professor Doutor da Faculdade de Ciências Médicas da Universidade Estadual de Campinas - Departamento de Enfermagem

***** Professor Doutor junto ao Departamento de Enfermagem Materno-Infantil e Saúde Pública da Escola de Enfermagem de Ribeirão Preto da Universidade de São Paulo
} 
mais próximo da população, é mais suscetível à participação popular, tem maior capacidade de conhecer a realidade local e, portanto, encontrar as possíveis soluções para os problemas detectados.

PIMENTA (1993) ressalta que a municipalização significará avanço se vier acompanhada da ampliação dos espaços de participação popular e controle social. A gestão municipal, estando mais próxima do usuário e sendo de menor abrangência, permite agilizar e implementar decisões que satisfazem os interesses da população.

O Ministério da Saúde considera que um dos maiores problemas para o processo de implantação do SUS está na área dos Recursos Humanos, principalmente no campo de sua preparação, relativos à integração ensino-serviço e à qualificação do pessoal. No campo da administração de recursos humanos, os problemas estão relacionados a: inadequação de composição das equipes de saúde frente às demandas sociais e epidemiológicas; inexistência de um sistema de informação de recursos humanos que subsidie a definição de diretrizes e implantação de políticas; inexistência de plano de carreiras para trabalhadores e outros problemas que servem de entraves para o funcionamento do Sistema.

Portanto, nos Recursos Humanos está uma possível solução das maiores questões da saúde. São eles que, sendo capazes de interferir positivamente na modificação das condições de vida e saúde da população e na expectativa de uma sociedade saudável, influirão diretamente na atenção à saúde e na terapêutica prestados aos indivíduos e coletividades. A saúde exige profissional ético e responsável, na medida em que este passe a reconhecer no usuário dos serviços um ser repleto de necessidades complexas e nem sempre objetivadas em uma doença.

A equipe de saúde não deve centrar suas atividades apenas em procedimentos técnicos e sim buscar refletir e atuar considerando a importância do envolvimento com o usuário e em ter uma relação mais próxima com as pessoas que buscam e/ou precisam de ajuda.

Assim, entendendo que o relacionamento humano nos serviços de saúde é um elemento essencial para melhorar a assistência, neste estudo analisamos como acontecem os relacionamentos entre o profissional e a clientela.

\section{REFERENCIAL TEÓRICO - ACOLHIMENTO À CLIENTELA}

Buscando obter dados sobre o relacionamento que se estabelece entre o profissional de saúde e o cliente, estudamos as habilidades interpessoais da pessoa que presta atendimento, segundo o "modelo de ajuda" de Robert R. Carchuff e Bernard G. Berenson, citado por MIRANDA \& MIRANDA (1990). São elas: atender, responder, personalizar e orientar. Também consideramos as fases pelas quais o usuário passa durante o processo de ajuda que são: envolver-se, explorar, compreender e agir.

FERREIRA (1988) aponta a palavra acolhimento como sendo: ato ou efeito de acolher, recepção; atenção, consideração; refúgio, abrigo e agasalho. QUINTÁZ (1995) elabora sua abordagem citando os biólogos, que com base em inúmeras pesquisas falam sobre o "acolhimento", comparando-o com a relação mãe-filho. A mãe seria um campo de amparo e acolhimento tendo a responsabilidade de cuidar de seu filho. Considerando esta relação nos serviços de saúde, o autor indica que os trabalhadores podem amparar a sua clientela, de modo que se torne responsável pelo desenvolvimento de seus usuários.

ENTRALGO (1983) nos faz pensar em acolhimento quando fala em "Relação de ajuda", na qual as pessoas que procuram ajuda são ao mesmo tempo objetos e agentes da ação; são objetos porque procuram ajuda, necessitam de ajuda, e agentes porque participam dessa ajuda através de opiniões e decisões. Nesta relação é imprescindível que a equipe de saúde esteja preparada adequadamente de modo a proporcionar uma relação clara e tranqüila para o usuário.

MIRANDA \& MIRANDA (1990) falam também sobre a relação de ajuda; citam que esta ocorre no encontro entre duas pessoas e será através desse encontro que o ajudador vai acolher o ajudado e construir a base de uma relação a dois. O relacionamento de ajuda é desenvolvido a cada encontro de modo a render o máximo para ambos. É como se o ajudador formasse a imagem do ajudado nos momentos iniciais, checando o quanto de abertura e disponibilidade pode esperar dele. Estes autores tiveram como fonte principal de seu trabalho o "modelo de ajuda" de Robert R. Carchuff e Bernard G. Berenson.

Os autores, desenvolvendo seu "modelo de ajuda", buscaram incessantemente uma operacionalização das habilidades interpessoais; compartilhar as habilidades de ajuda com o maior número de pessoas; pais, professores, patrões, profissionais de saúde, religiosos, aquelas pessoas que normalmente exercem influência marcante na vida dos outros - além dos profissionais da área da "saúde mental" - psiquiatras, psicólogos, orientadores, conselheiros. A todo esse grupo de pessoas significativas chamou de ajudadores; e ao grupo de pessoas que de uma forma ou de outra, recebem sua influência ou com eles interagem, de ajudados.

Neste modelo constam as principais habilidades 
interpessoais do ajudador, sendo: 1) atender é comunicar de maneiras não verbais, disponibilidade e interesse pelo ajudado; 2) responder é comunicar compreensão pelo ajudado; 3 ) personalizar é mostrar ao ajudado sua parcela de responsabilidade no seu problema; 4) orientar é avaliar com o ajudado, as alternativas de ação possíveis e facilitar a escolha de uma delas.

Também segundo este modelo, as fases pelas quais o ajudado passa durante o desenrolar do processo de ajuda são: 1) envolver-se: capacidade de se entregar ao processo de ajuda; 2) explorar: capacidade de avaliar a situação real em que se encontra no momento do processo de ajuda; 3 ) compreender: estabelecer ligações de causa e efeito entre os elementos presentes em sua vida; 4) agir: movimentar-se do ponto onde está para onde quer chegar, escolhendo o melhor caminho.

O final do processo de ajuda ocorre quando o ajudado se torna seu próprio ajudador.

Segundo MIRANDA \& MIRANDA (1990) o ajudado é uma pessoa a quem faltam algumas habilidades de vida. O ajudador precisa ter disponibilidade interna para ajudar o outro e para amá-lo no decorrer do processo.

Estes autores trazem a palavra "acolhendo", dentro deste processo de ajuda. Definem como sendo: "receber o ajudado calorosamente ao iniciar o encontro com ele, sendo que ao acolher o ajudado, devo transmitirlhe receptividade e interesse, de modo que ele se sinta valorizado". Consideram que existem algumas maneiras de acolher, como: dirigir-se ao ajudado usando o seu nome; cumprimentá-lo e individualizá-lo.

CAMPOS (1994) considera que para se assegurar a qualidade do cuidado e a legitimação dos serviços públicos pelos usuários, é preciso que se tenha em mente as noções de "vínculo de acolhida" e de responsabilizarse a equipe pelo cuidado integral da saúde coletiva e individual.

MATUMOTO (1998) em seu estudo sobre o acolhimento em uma unidade de saúde do município de Ribeirão Preto assinala a importância de compreendermos o acolhimento como um processo que se inicia mesmo antes do usuário chegar ao serviço de saúde, uma vez que este se estrutura para o atendimento definindo espaços específicos, formas de atender necessidades de saúde, ou seja, define um certo "modo de responder" às necessidades que são expressas pela clientela. Enfatiza que o acolhimento apresenta alguns componentes, tais como: a mútua-representação entre trabalhador e usuário; a objetivação do que é saúde/doença e do que é problema/ necessidade de saúde; a comunicação e escrita e responsabilizar-se pelo trabalho e pela ajuda ao outro.

Segundo MERHY (1994) o usuário espera que a relação que possa se estabelecer entre ele e o trabalhador de saúde, seja capaz de gerar um acolhimento que permita uma atuação sobre o seu sofrimento, o seu problema. Há uma grande expectativa por parte do usuário, de que o trabalhador - individual ou coletivamente - responda com resolutividade ao seu problema. Espera-se que o conjunto das ações de saúde ao qual se dispõe a se submeter, lhe traga benefícios, isto é, consiga alterar sua situação. Enfim, a sua grande expectativa é que as ações de saúde sejam efetivas e o satisfaçam.

Neste estudo procura-se entender como ocorre o acolhimento pelos trabalhadores que prestam serviços públicos de saúde à sua clientela, pois notamos que aqueles, muitas vezes se posicionam de forma distante, não demostrando receptividade e interesse de modo que o cliente se sinta valorizado. Nos cuidados prestados aos clientes, existe maior preocupação na realização dos procedimentos técnicos. Esta postura da equipe de saúde se revela através de atitudes tais como: Aproximação ao cliente; Cumprimento; Individualização; Concentração no atendimento e Demonstração de envolvimento ou sentimento em relação aos problemas do cliente.

\section{OBJETIVO}

Observar e analisar o relacionamento que se estabelece entre os auxiliares de enfermagem e a clientela em Unidades Básicas de Saúde, enfocando o acolhimento.

\section{METODOLOGIA}

Para avaliarmos o relacionamento das pessoas que procuram os serviços de saúde com os profissionais que aí trabalham observamos duas unidades básicas de saúde. Para tanto, foi encaminhada uma carta à Secretaria Municipal de Saúde de Ribeirão Preto, solicitando permissão para realização do estudo.

Após autorização do secretário e dos gerentes das unidades, foram planejadas as observações. Uma das unidades selecionadas, que aqui chamaremos de unidade "A", estava passando pelo processo de territorialização******. A outra unidade "B" foi escolhida por tratar-se de uma unidade típica da rede municipal e pela facilidade de acesso.

****** A territorialização tem como base, pensar o território; segundo MENDES (1995), "o estabelecimento desta base territorial é um passo básico para a caracterização da população e de seus problemas de saúde, bem como o dimensionamento do impacto do sistema sobre os níveis de saúde dessa população e, também, para a criação de uma relação de responsabilidade entre os serviços de saúde e sua população adscrita" 
Foram considerados como sujeitos das observações, os auxiliares de enfermagem que prestaram atendimento nas salas de pré e pós consultas destas unidades, bem como os clientes que procuraram ajuda nas UBS. Em horários de trabalho rotineiro, foram observados 7 auxiliares de enfermagem, e o tempo de exercício profissional, variou entre 10 a 20 anos de serviço. Os clientes observados, num total de 35 , eram capazes de manter diálogo e não havia deficiências perceptíveis nos órgãos de comunicação.

A observação durou 20 dias em cada unidade; um roteiro orientou nosso trabalho, procurando abordagens sobre o relacionamento que se estabelece entre o auxiliar de enfermagem e o cliente, durante o atendimento destes nas salas de pré e pós consultas (Anexo).

Assim sendo, foi uma observação sistematizada, orientada e não casual direta, com o observador frente ao fato e não participante, sem interferência no comportamento das pessoas observadas (DANIEL, 1981).

Foi utilizada para o registro a técnica do relato cursivo. Esta técnica permite registrar todo o evento no momento em que ocorre com maior número de dados possíveis, sem interpretação do observador (BOMTEMPO, 1975).

A partir da observação realizada, obtivemos dados e subsídios para a análise de como ocorre o acolhimento à clientela em Unidades Básicas de Saúde.

\section{RESULTADOS E DISCUSSÃO}

As unidades trabalham com consultas eventuais e pré-agendadas, oferecendo as seguintes áreas: Clínica Médica, Ginecologia e Obstetrícia, Pediatria, atendimento odontológico, além de outras atividades como curativos, aerosóis, aplicações de medicamentos e visitas domiciliárias.

Possuem três salas para realização das pré e pós consultas; sendo uma sala para cada área assistencial: mulher, criança e adulto. Em cada sala está presente uma auxiliar de enfermagem e todas as profissionais observadas neste estudo são do sexo feminino.

Na Unidade "A", foi verificado que a gerente está atenta à realização das atividades assistenciais desenvolvidas pelos profissionais dentro e fora da unidade, como por exemplo, avaliação dos relatórios das visitas domiciliárias realizadas, encaminhamentos de cartas a clientes faltosos na sala de vacinação e outras.

Nesta unidade, é determinado pela gerente que se faça mensalmente um rodízio na escala das auxiliares que prestam atendimento nas salas da clínica médica e pediatria. Atende a uma área de aproximadamente $8 \mathrm{mil}$ habitantes e a população apresenta nível socioeconômicocultural semelhante.

Na Unidade "B", observamos que a gerente tem maior preocupação com as questões administrativas, como, a maneira de proceder com clientes que pertencem a outras unidades, retornos, escalas de funcionários, etc.

O rodízio da escala das auxiliares é feito semanalmente nas salas de ginecologia e clínica médica. A unidade atende a 15.638 habitantes e a população apresenta diferentes níveis socioeconômicos-culturais.

Nesta etapa de discussão é descrito o relacionamento desenvolvido entre a profissional e o usuário com vistas àquelas habilidades interpessoais citadas por MIRANDA \& MIRANDA (1990).

Para o profissional imbuído da competência de ajuda as habilidades são: atender, responder, personalizar e orientar. Aquelas atribuídas ao usuário que recebe ajuda são: envolver-se, explorar, compreender e agir.

Após leitura cuidadosa dos registros de observação dos 35 doentes selecionados cujas auxiliares tiveram um relacionamento interpessoal foram escolhidos casos "típicos" das duas unidades, os quais serão apresentados a seguir.

\section{CASO 1 - UNIDADE A}

A mãe chegou com seu filho na unidade para consulta previamente agendada há 7 dias. $\mathrm{Na}$ sala de pré-consulta da pediatria são verificados peso e altura da criança. Durante os procedimentos técnicos, a mãe relatou que o filho foi mordido por um cachorro há 48 horas, mas que não o trouxe na Unidade, porque a dona do cachorro disse que o mesmo era vacinado. Durante o atendimento, a auxiliar falou para a mãe que a sua conduta foi inadequada, e a orientou para ir até a sala de vacina. A mãe se dirige para outra sala onde questiona o caso do filho com outra auxiliar, $e$ pergunta se realmente é necessária a vacinação. A funcionária imediatamente a encaminha para a sala de vacina explicando a necessidade do procedimento. (Observação - 1)

Neste caso a primeira auxiliar não apresentou nesta situação a habilidade inicial da relação de ajuda, isto é, não conseguiu responder de maneira satisfatória à necessidade da cliente.

Ao chegar na sala de vacinação, a auxiliar do local a interroga com perguntas pertinentes ao caso, como por exemplo: se o cachorro tem dono, qual o endereço, a quanto tempo levou a mordida, como está a carteira de vacina. Após a vacinação anti-rábica, a criança foi consultada pelo 
pediatra e orientada na sala de pós-consulta quanto ao uso de medicamentos prescritos pelo médico e quanto à aplicação da $2^{a}$ dose da vacina. (Observação - 1)

Diante deste fato, notamos que: no primeiro contato da usuária com a funcionária, na sala de préconsulta houve preocupação apenas com a realização dos procedimentos técnicos rotineiros. A funcionária não personalizou o atendimento, pois não se sentia responsável pelo problema da usuária, não perguntando a queixa e, portanto, não demonstrando interesse e envolvimento pelo seu problema. A mãe também estava pouco envolvida com o problema. Ela procurou a unidade para consultar o seu filho que coincidentemente havia sido mordido por cachorro há dois dias.

Acreditamos que se mãe não dissesse o acontecido, talvez este fato passasse desapercebido.

Notamos, que embora a primeira auxiliar tenha orientado a mãe para a vacinação, esta preferiu confirmar a informação com outra pessoa antes da realização do procedimento. Podemos dizer que:

- A funcionária não demonstrou confiança à mãe. A maneira como ela se expressou não foi o suficiente para que a mãe procurasse a sala de vacina. Isto confirma a falta de confiabilidade no profissional e conseqüentemente no serviço.

Entendemos que a pessoa a ser ajudada tem as suas dificuldades e que merecem atenção e respeito por parte de quem presta ajuda. O profissional deve ter a habilidade para abordar o usuário de maneira mais adequada possível, de modo que ele se sinta valorizado. É preciso dirigir a ele chamando pelo nome, cumprimentálo e individualizá-lo. Isto transmite ao usuário uma sensação de ser importante para o profissional, personalizando as relações.

Analisando este caso de acordo com o nosso referencial teórico, podemos dizer que a primeira auxiliar não apresentou as habilidades interpessoais, pois não houve interesse, motivação e individualização ao abordar a cliente; devemos citar que ela faz uma orientação, mas sem sucesso de sua parte; notamos falta de segurança da profissional ao se expressar.

O tempo dispensado pela profissional neste atendimento durou menos do que três minutos.

A segunda auxiliar, ao ser abordada pela cliente, além de explicar da necessidade da vacinação, leva-a até a sala de vacina, e fica aguardando a realização do procedimento, participando assim ativamente do atendimento desta usuária.

Neste caso a atenção, disponibilidade, interesse e envolvimento demonstrados nos leva a dizer que, prevaleceram as habilidades atender, responder, personalizar, orientar e envolver-se; conseqüentemente podemos afirmar que houve acolhimento, pois segundo MIRANDA \&
MIRANDA (1990), podemos considerar que se há interesse, disponibilidade por parte daquele que presta ajuda, significa que está ocorrendo acolhimento ao ajudado. Também segundo estes autores, se acolhe o cliente quando se the transmite receptividade de modo a ele se sentir valorizado.

Por outro lado, pela parte da usuária, foi notado que apesar da situação do filho, havia pouco envolvimento e confiança no atendimento recebido pela primeira funcionária. A usuária relatou o "problema" do filho casualmente durante o atendimento; não parecia preocupada com a questão; após a orientação, a mãe ficou aparentemente confusa e apreensiva; e antes de uma tomada de decisão, procurou outra profissional em busca de uma resposta esclarecedora e convincente.

\section{CASO 2 - UNIDADE A}

A mãe trouxe o filho para consultar. Na sala de pré-consulta da Pediatria foram verificados o peso e a altura da criança rapidamente e registrado no prontuário. Sem perguntar qualquer outra informação a auxiliar falou para a mãe esperar no banco pela chamada do médico para a consulta. Após a realização da mesma, mãe e filho retornam a sala em que está a auxiliar para a pós-consulta. A funcionária não faz uma leitura das anotações realizadas pelo pediatra. Orienta quanto ao uso de medicamentos e retorno. Dispensandoos a seguir. (Observação - 2)

Também observamos aqui um distanciamento entre a profissional e a usuária, não havendo um relacionamento personalizado, no qual a atenção à saúde enfocasse a criança de forma integral. $\mathrm{O}$ atendimento da auxiliar restringiu-se aos procedimentos rotineiros de encaminhar para e dispensar da consulta médica, não questionando a queixa, os desejos e a situação de saúde da criança. Não houve uma aproximação e envolvimento com o binômio mãe-criança. Não havendo portanto acolhimento à clientela.

Este cenário apresentado caracteriza a maioria das observações nas Unidades de Saúde onde realizamos este estudo em quaisquer das áreas de atendimento (adulto, mulher e criança). É típico de uma atenção do tipo "Pronto Atendimento", na qual o usuário com queixa procura por consulta médica. Na unidade, além do médico, nenhum outro profissional conhece o problema ou a queixa. Este tipo de atendimento é concluído com uma conduta, em geral, medicamentosa.

O acolhimento da clientela pela enfermagem, que é necessário na prevenção de doenças e na promoção à saúde, não tem sido praticado nestes casos. 


\section{CASO 3 - UNIDADE B}

Durante a permanência na sala de pré e pós consulta da ginecologia observamos que a auxiliar de enfermagem do local além de realizar os atendimentos nesta sala, auxilia o ginecologista em alguns procedimentos como colocação de DIU, drenagem de pequenos abcessos no órgão genital e outros.

Nesta sala observamos que as clientes chegavam e falavam espontaneamente suas queixas, antes mesmo de serem questionadas pela profissional; isto parece ocorrer pelo fato da funcionária ser moradora do bairro próximo à Unidade e conhecer a maior parte das pessoas que buscam atendimento. Foi verificado envolvimento da profissional para com os problemas das usuárias. Antes mesmo de procurar a recepção para agendar consulta, algumas usuárias procuram-na a fim de pedir opinião se devem ou não marcar consulta.

Há, portanto, confiança na profissional; devido ao envolvimento e atenção dispensada às usuárias, esta profissional passa a ser muito solicitada. O seu atendimento dura em torno de sete minutos.

Algumas vezes não há vaga para o atendimento, a Unidade está sobrecarregada e a auxiliar sensibilizada com o problema de uma usuária procura o médico para tentar atender a cliente, assim expressando-se:

Aux. A-Doutor, a paciente está querendo consultar pois acha que está grávida. Ela está preocupada. Posso agendar? (Observação 3)

A auxiliar neste caso demonstrou atenção, interesse e compreensão para com o problema da usuária. Segundo o modelo de ajuda de Robert. R. Carchuff, a profissional apresentou visível a habilidade atender, pois teve olhar dirigido ao cliente, conseguiu demonstrar interesse, consideração, respeito e boas maneiras. Acolheu a todos do mesmo modo, sem distinção. Notamos também outras habilidades, como responder, personalizar, envolver e compreender; podemos então dizer que houve acolhimento por parte desta profissional.

Contudo, na pós-consulta, houve maior preocupação em fazer orientações sobre o uso de medicamentos e observou-se dificuldade para fazer uma análise da consulta médica a fim de orientar as ações possíveis que poderiam facilitar a resolução de outros problemas da usuária.

Neste caso, percebeu-se que a profissional apresenta a habilidade orientar limitada, que segundo o modelo de ajuda citado, seria: tentar escolher junto com a usuária as ações possíveis para o seu restabelecimento. Para isso seria necessário uma avaliação por parte da profissional desde o momento da chegada da usuária até a pós-consulta, quando não bastaria orientar somente uso de medicamentos e retorno, e sim analisar com cuidado as informações prescritas pelo médico no prontuário, as orientações previstas da enfermagem para o caso e fazer as orientações necessárias à usuária.

Esta dificuldade da profissional em realizar uma orientação completa, parece não interferir no relacionamento preestabelecido com a usuária durante a pré-consulta; por outro lado, a falta de informações poderá prejudicar o tratamento e relacionamentos futuros.

Pela falta de informações recebidas durante a pósconsulta, uma das fases pelas quais a pessoa que recebe ajuda passa durante o tratamento pode ficar prejudicada. Em particular, neste caso, falamos da fase Agir, onde o usuário deve progredir no tratamento através da escolha de um caminho correto, que sem ajuda e orientação do profissional pode tornar-se inviável.

\section{CASO 4 - UNIDADE B}

Considerando agora a sala de pré e pós-consulta da pediatria, com relação ao relacionamento existente entre o profissional e o usuário, notamos que este se envolve completamente na relação.

Assim que a mãe entrou nesta sala, acompanhada pelo filho, a profissional conseguiu abordar a mãe sobre o problema da criança que a trouxe ali, de forma muito segura e tranqüila:

Bom dia, mãe B..., como vai esta pequena? O que aconteceu para a senhora procurar a gente? Senta um pouquinho, vamos conversar. (Observação - 4)

A mãe se sentou e falou tudo o que estava ocorrendo, sem pressa, tentando comunicar as características do problema. A auxiliar ouviu atentamente, sem interromper a usuária, deixando a situação fluir. Após isto, foram realizados os procedimentos técnicos, verificados peso, altura e temperatura. Foi feito o gráfico de crescimento da criança e orientada a mãe a aguardar a consulta médica. $\mathrm{O}$ atendimento desta funcionária tem em média a duração de oito minutos.

$\mathrm{Na}$ pós-consulta, a auxiliar, com base nas condutas médicas prescritas no prontuário orientou a mãe quanto às ações que deveriam ser realizadas para o tratamento adequado da sua filha. Vejamos o diálogo:

Auxiliar-Mãe B..., agora eu vou lhe dizer o que a senhora terá que fazer e que a médica já deve ter lhe dito; mas eu vou reforçar algumas coisas.

Mãe-Tudo bem.

Auxiliar: - A médica deve ter lhe falado que a sua criança é alérgica. Então a senhora terá que tomar alguns cuidados com relação à limpeza da casa, por exemplo: não varrer os quartos, apenas passar pano úmido; retirar 
os bichos de pelúcia do quarto da menina, porque eles juntam poeira; abrir a janela para deixar o sol entrar no quarto; deixar sempre bem limpas as cobertas. Com esses cuidados ela já vai melhorar bem, a senhora vai ver! Tem alguma dúvida do que eu falei? Pode perguntar?

Mãe - Fica tranqüila, eu entendi tudo. Muito obrigada.

Auxiliar - A senhora quer que eu escreva isto num papel?

Mãe - Se você quiser eu acho bom.

Após este diálogo a auxiliar faz as orientações sobre o uso de medicamentos e descreve numa

folha as recomendações feitas anteriormente.

(Observação - 4)

Vimos, por meio desta observação que a usuária se entregou no processo de ajuda. Ela conseguiu compreender a sua real situação, o problema e quais as ações que deveriam ser realizadas para amenizá-lo.

É possível perceber através da análise do diálogo anterior que, um tratamento, para ser feito adequadamente, não depende apenas de uma consulta médica e uso de medicamentos, são necessários atenção, respeito, compreensão e entrega na relação profissional - usuário de ambas as partes. É preciso que o profissional seja capaz de acolher o usuário.

Não basta apenas agendá-lo, realizar procedimentos técnicos, questionar a queixa e orientar sobre o uso de medicamentos. É preciso mais.

A qualidade no atendimento ao usuário implica em comunicar disponibilidade e interesse, demonstrar compreensão e ajudá-lo a descobrir alternativas para o seu problema.

A observação deste atendimento foi gratificante, pois a profissional apresentou, além das habilidades interpessoais necessárias para que haja acolhimento, que são atender, responder, personalizar, também foi notada a habilidade Orientar. O usuário, neste caso sente-se privilegiado por receber este atendimento. Segundo o modelo de ajuda de Carchuff \& Berenson, este usuário passou pelas fases de envolver-se, explorar e compreender, necessárias durante o processo, facilitando assim a fase de agir que é a última para a realização do tratamento.

\section{CONSIDERAÇÕES FINAIS}

Foi possível observar que existem profissionais que acolhem a clientela. Numa mesma Unidade de Saúde encontramos diversas posturas e maneiras diferentes de se comunicar com o usuário, que conformam posturas polares de acolhida e não acolhida.

Consideramos que a diversidade é positiva. Contudo, da forma como se apresentou nas observações pareceu-nos não haver um projeto das Unidades de orientar o trabalho dos profissionais para o acolhimento. Um fator presente nas observações de campo foi que houve acolhimento ao cliente quando o tempo dispendido no atendimento foi igual ou superior a cinco minutos.

A construção de uma relação de ajuda entre o profissional e o cliente depende de ambos. O profissional deve saber administrar a situação, apresentando comportamentos de acolhida, verbais e não-verbais. $\mathrm{O}$ usuário deve demonstrar disponibilidade interna e envolvimento durante o relacionamento, participando da busca de ações possíveis para a resolução de seus problemas ou satisfação de seus desejos e necessidades.

Sendo uma interação, a relação de ajuda sofre condicionamentos tanto da formação dos profissionais quanto da situação de cidadania. O compromisso profissional e os direitos dos usuários são faces complementares e interdependentes deste mesmo processo de melhora da qualidade do atendimento, do qual o acolhimento é parte significativa.

O usuário que busca por atenção à saúde deve ser "sujeito" na situação e não simplesmente "objeto" destinado a receber tratamento médico. Procedimentos rotineiros devem ser constantemente reavaliados e desenvolvidos a partir da avaliação da pertinência em cada situação específica.

Assim, o acolhimento deve ser incorporado aos procedimentos das Unidades de Saúde, ao mesmo tempo, em que necessita transcender o caráter de rotina do cotidiano. Quer dizer, a relação de ajuda permeia todas as situações de atendimento em que profissional e clientela se encontram, demandando uma ação contínua de formação, supervisão e estímulo para que se torne efetiva.

\section{RECEIVING CLIENTS: A STUDY IN BASIC HEALTH UNITS IN THE CITY OF RIBEIRÃO PRETO}

This study was based on the analysis of the relationship established between nursing auxiliaries and their clientele in two Basic Health Units at the time of clients' reception. The theoretical framework used was that of the "help model", whose elements are: attending, responding, personalizing, giving directions, becoming involved, exploring, understanding and acting. Four typical cases are presented, which show that the relationships are not always personalized, the client and the auxiliary do 
not become involved in the relationship and that there is more concern about the development of technical abilities than about reception. There are different communication attitudes at the same unit. The reception process must be incorporated to the health unit procedures at the same time it must transcend the routine character of daily activities.

KEY WORDS: nursing, nursing processes, relationship

\section{ACOGIMIENTO A LA CLIENTELA: ESTUDIO EN UNIDADES BÁSICAS DE SALUD EN EL MUNICÍPIO DE RIBEIRÃO PRETO}

Teniendo como referencial teórico el "modelo de ayuda" cuyos elementos son: atender, responder, personalizar, orientar, envolverse, explorar, comprender, actuar, se realizó el estudio analizando la relación que se establece entre el auxiliar de enfermería y la clientela en dos unidades de salud, enfocando el acogimiento. Cuatro casos típicos son presentados, mostrando que no siempre las relaciones son personalizadas, cliente y auxiliar no se envuelven en la relación, hay mayor preocupación con las habilidades técnicas que con el acogimiento. En la misma unidad, hay posturas diversas en el acto de comunicarse. El acogimiento todavía debe ser incorporado a los procedimientos de las unidades, al mismo tiempo que debe transcender al carácter rutinário de lo cotidiano.

TÉRMINOS CLAVES: enfermería, procesos de enfermería, relaciones interpersonales

\section{ANEXO}

\section{INSTRUMENTO DE OBSERVAÇÃO}

Em relação ao Profissional de Saúde:

1. O que está sendo feito para acolher as pessoas que procuram o serviço:

a. Postura do Profissional diante do cliente - a atenção, prestação de serviços, expressões verbais e não verbais do profissional.

b. Interesse pela condição do cliente - demonstração de preocupação com a situação atual do cliente, demonstrando

\section{REFERÊNCIAS BIBLIOGRÁFICAS}

01. BOMTEMPO, E. Observação. Um método para estudo do comportamento. In: WITTER, G.P. Ciência, ensino e aprendizagem. São Paulo: Alfa - Omega, 1975.

02. CAMPOS, G.W.S. Considerações sobre a arte e a ciência da mudança: revolução das coisas e reforma das pessoas. O caso da saúde. In: CECÍLIO, L.C. de O. (org.). Inventando a mudança na saúde. São Paulo: Hucitec, 1994. Cap. 2, p. $29-87$.

03. DANIEL, L.F. A enfermagem planejada. 3. ed. São Paulo: EPU, 1981.

04. ENTRALGO, P. La relación médico-enfermo: história y teoria. Madrid: Alianza Editorial, 1983.

05. FERREIRA, A.B. de H. Dicionário Aurélio básico da língua portuguesa. Rio de Janeiro: Nova Fronteira, 1988.

06. MATUMOTO, S. O acolhimento: um estudo sobre seus componentes e sua produção em uma unidade da rede básica de serviços de saúde. Ribeirão Preto, 1998. 219p. Dissertação (Mestrado) - Escola de Enfermagem de Ribeirão Preto, Universidade de São Paulo. vontade de ajudá-lo e favorecendo condições necessárias para o seu desenvolvimento.

2. O que está sendo feito, e que corresponde ao acolhimento

a. Tipo de atendimento - atendimento centrado nos procedimentos técnicos ou na pessoa/dispendido.

b. Tempo - para cada atividade, pré e pós-consulta, disponibilidade do profissional

Em relação ao Cliente:

1. Postura diante do profissional de saúde - comportamento, atitudes, interesse pelo próprio estado de saúde.

2. Conhecimento sobre condição de Saúde ou Doença

07. MENDES, E.V. O processo social de distribuição da saúde, In: MENDES, E.V. (org.). Distrito sanitário. 3. ed. São Paulo: Hucitec/Abrasco, 1995. (Saúde em Debate, 55).

08. MERHY, E.E. Em busca da qualidade dos Serviços de Saúde: os Serviços de Porta Aberta para a saúde e o modelo técnico-assistencial em defesa da vida (ou como aproveitar os ruídos do cotidiano dos serviços de saúde e colegiadamente reorganizar o processo de trabalho na busca da qualidade das ações de saúde). In: CECÍLIO, L.C. de O. (org.). Inventando a mudança na saúde. São Paulo: Hucitec, 1994. cap. 3, p. 117 -160.

09. MIRANDA, C.F.; MIRANDA, M.L. Construindo a relação de ajuda. 6 . ed. Belo Horizonte: Editora Crescer, 1990.

10. PIMENTA, A.L. O SUS e a municipalização à luz da experiência concreta. Saúde e Soc., São Paulo, v. 2 , n. 1, p. $25-40,1993$.

11. QUINTÁZ, A.L. O amor humano: seu sentido e alcance. Tradução por Ricardo Aníbal Resenbuch. Petrópolis: Vozes, 1995. 